\title{
Comparison of Solid-State Microwave Annealing with Conventional Furnace Annealing of Ion-Implanted SiC
}

\author{
SIDDARTH G. SUNDARESAN, ${ }^{1}$ MULPURI V. RAO,${ }^{1,6}$ YONGLAI TIAN, ${ }^{2}$ \\ JOHN A. SCHREIFELS, ${ }^{3}$ MARK C. WOOD,${ }^{4}$ KENNETH A. JONES, ${ }^{4}$ \\ and ALBERT V. DAVYDOV 5 \\ 1.-Department of Electrical and Computer Engineering, George Mason University, Fairfax, VA \\ 22030, USA. 2.-LT Technologies, Fairfax, VA 22033, USA. 3.-Department of Chemistry \\ and Biochemistry, George Mason University, Fairfax, VA 22030, USA. 4.-Sensors and Electron \\ Devices Directorate, Army Research Laboratory, Adelphi, MD 20783, USA. 5.-Metallurgy \\ Division, National Institute of Standards and Technology, Gaithersburg, MD 20899, USA. \\ 6.-E-mail: rmulpuri@gmu.edu
}

Rapid solid-state microwave annealing was performed for the first time on $\mathrm{N}^{+}$-, $\mathrm{Al}^{+}$-, and $\mathrm{B}^{+}$-implanted $\mathrm{SiC}$, and the results were compared with the conventional furnace annealing. For microwave annealing, temperatures up to $2,000{ }^{\circ} \mathrm{C}$ were attained with heating rates exceeding $600{ }^{\circ} \mathrm{C} / \mathrm{s}$. An $1,850{ }^{\circ} \mathrm{C} / 35 \mathrm{~s}$ microwave anneal yielded a root-mean-square (RMS) surface roughness of $2 \mathrm{~nm}$, which is lower than the $6 \mathrm{~nm}$ obtained for $1,500{ }^{\circ} \mathrm{C} / 15$ min conventional furnace annealing. For the $\mathrm{Al}$ implants, a minimum room-temperature sheet resistance $\left(R_{s}\right)$ of $7 \mathrm{k} \Omega / \square$ was measured upon microwave annealing. For the microwave annealing, Rutherford backscattering (RBS) measurements indicated a better structural quality, and secondary-ion-mass-spectrometry (SIMS) boron implant depth profiles showed reduced boron redistribution compared to the corresponding results of the furnace annealing.

Key words: Implantation, solid-state microwave annealing, silicon carbide

\section{INTRODUCTION}

A large bandgap, high breakdown electric field, high thermal conductivity, and outstanding chemical inertness make silicon carbide (SiC) the semiconductor material of choice for fabricating high-temperature, high-power, and high-frequency devices. ${ }^{1}$ An indispensable technique for planar selective area doping of $\mathrm{SiC}$ devices is ion implantation. Ion implantation is currently used for creating active regions and edge terminations in various $\mathrm{SiC}$ devices, namely, in MESFETs, ${ }^{2}$ MOSFETs, ${ }^{3}$ JFETs, ${ }^{4}$ Schottky, ${ }^{5}$ junction barrier Schottky, ${ }^{6}$ and p-i-n diodes. ${ }^{7}$ Annealing is a necessary step after ion implantation for removing lattice damage and electrically activating the implanted ions. In the case of $\mathrm{SiC}$, post-implantation annealing needs to be performed at temperatures $>1,500{ }^{\circ} \mathrm{C}$ to achieve reasonable implant activation. ${ }^{7,8}$ These

(Received June 20, 2006; accepted October 27, 2006;

published online February 6, 2007) anneals are conventionally performed in resistively or inductively heated ceramic furnaces. ${ }^{7,8}$ However, there are several critical problems with conventional anneals. One of them is an increased surface roughness with increasing annealing temperature, due to sublimation and redeposition of constituent species on the substrate surface (a process, which is popularly known as "step bunching"), which limits the maximum annealing temperature. This limitation on the annealing temperature may result in a nonoptimum electrical activation, which leads to higher contact and channel region resistances. Step bunching has been observed for implants of all common $\mathrm{SiC}$ dopant species, including boron, ${ }^{9}$ nitrogen, ${ }^{10}$ aluminum, ${ }^{11}$ and phosphorus. ${ }^{12}$ Excessive surface roughness has negative effects on the performance of $\mathrm{SiC}$ devices, one of which is a degradation of inversion layer mobility leading to a high on-resistance of SiC MOSFETs. ${ }^{13}$ Another undesirable effect of conventional annealing is outand in-diffusion of the boron implant. ${ }^{14}$ 
Increasing both the annealing temperatures and the ramping rates are key factors in solving the critical problems associated with the post-implantation annealing of SiC. ${ }^{15-17}$ An increase in the annealing temperature will be the most effective means of achieving a near complete activation of the implant, because the damage recovery and dopant activation are essentially thermal diffusion-related processes. ${ }^{16}$ Furthermore, the impurity solubility also increases with increasing annealing temperature, resulting in a high implant activation efficiency. However, the annealing time should be kept short enough to minimize step bunching. Recently, several capping techniques have been proposed to suppress SiC surface roughness and dopant outdiffusion during conventional annealing, which is performed for durations of $10 \mathrm{~min}-30 \mathrm{~min} .{ }^{18-23}$ However, these techniques have their maximum temperature limitations and require complicated processing steps. Also there is always the issue of their reliable removal after postimplantation annealing.

To avoid surface deterioration caused by slow heating and cooling rates of conventional resistive heating furnaces used for processing $\mathrm{SiC}$, new ultrafast annealing techniques need to be explored. Halogen lamp and laser-based rapid thermal processing techniques suffer from problems such as a possible limitation on the maximum achievable annealing temperature, surface melting, a large residual defect density, and redistribution of the implants. ${ }^{17,18}$ Microwave heating may solve many of these problems.

Microwave annealing provides very fast heating and cooling rates and a good control over the annealing time when the SiC sample is encased in microwave transparent materials. The heating rate for solid-state microwave annealing is very high because the microwaves are absorbed only by the semiconductor sample and not by the surroundings. The cooling rate is also high because the ambient surrounding the sample is not heated during the annealing process. Earlier, we reported ${ }^{21}$ results on the microwave annealing of implanted SiC, where a microwave cavity (resonator) operating in the single $\mathrm{TE}_{103}$ mode was used. However, the heating rate of these cavity resonators was found to be limited to $200^{\circ} \mathrm{C} / \mathrm{min} .{ }^{21}$ In addition, the cavity resonators may not be suitable for annealing large size wafers and for batch processing. Recently, a solid-state microwave RTP system was developed by LT Technologies.* This novel solid-state microwave heating technique may alleviate these problems due to its advantages, such as swift electronic tuning, as opposed to the mechanical tuning of cavity resonators, and variable operating frequencies, as opposed to a fixed resonant frequency for a cavity.

*Certain commercial equipment, instrument, or materials suppliers are identified in order to specify the experimental procedure adequately and do not imply endorsement by the NIST.
In this article, we present our results on nitrogen-, aluminum-, and boron-implanted $4 \mathrm{H} / 6 \mathrm{H}-\mathrm{SiC}$ annealed by solid-state microwave heating. The surface morphology, electrical characteristics, surface oxidation, structural quality, and implant redistribution of the annealed samples are examined. Results on microwave annealed samples are compared with the results on the samples cut from the same wafers annealed by conventional furnace annealing.

\section{EXPERIMENTAL DETAILS}

\section{Solid-State Microwave Heating System}

The solid-state microwave rapid thermal processing (RTP) unit used in this work, with the schematic shown in Fig. 1, has three main building blocks: (1) a variable frequency microwave power source, which consists of a signal generator and a power amplifier; (2) a heating system, which consists of a tuning and coupling circuit and a heating head; and (3) a measurement and control system, which consists of a network analyzer, a computer, an optical pyrometer, and other equipment.

Microwave power generated by the variable frequency power source is coupled to a $\mathrm{SiC}$ sample through the heating head. The sample temperature is monitored by an infrared pyrometer. The SiC sample emissivity was measured as 0.74 using a blackbody source, and this emissivity value was keyed into the pyrometer for all temperature measurements of this study. Figure 2 shows a typical $1,800{ }^{\circ} \mathrm{C}$ annealing cycle used in this work for implanted SiC. Heating rates $>600{ }^{\circ} \mathrm{C} / \mathrm{s}$ have been achieved because the microwave energy exclusively couples to the $\mathrm{SiC}$ sample. The cooling rates are also in excess of $400{ }^{\circ} \mathrm{C} / \mathrm{s}$.

\section{Other Experimental Details}

In this study, for the single- and multiple-energy $\mathrm{N}^{+}$implantations, we used $3.5^{\circ}$ off-axis (0001)oriented Si-face p-type $\left(5 \times 10^{17} \mathrm{~cm}^{-3}\right)$ bulk $6 \mathrm{H}$-SiC crystals, as well as p-type $\left(5 \times 10^{15} \mathrm{~cm}^{-3}\right)$ epitaxial layers grown on bulk $6 \mathrm{H}-\mathrm{SiC}$ substrates. Nitrogen implants were performed at both room temperature (RT) and $700{ }^{\circ} \mathrm{C}$. Single-energy $(50 \mathrm{keV}) \mathrm{N}^{+}$implants were performed for an implant dose of $3.1 \times 10^{15} \mathrm{~cm}^{-2}$. Two multiple-energy $\mathrm{N}^{+}$implants were performed, one in the energy range 15$250 \mathrm{keV}$ and another deeper implant in the energy range $50 \mathrm{keV}-4 \mathrm{MeV}$. The total implant doses were $2.7 \times 10^{15} \mathrm{~cm}^{-2}$ and $1.57 \times 10^{15} \mathrm{~cm}^{-2}$, respectively. Multiple-energy implants were designed to obtain uniform doping concentrations. Multiple-energy $(25-200 \mathrm{keV}) \mathrm{Al}^{+}$implantations were performed (at $600{ }^{\circ} \mathrm{C}$ ) into a semi-insulating on-axis $4 \mathrm{H}-\mathrm{SiC}$ wafer. The total implant dose was $2.7 \times 10^{15} \mathrm{~cm}^{-2}$. A $200 \mathrm{keV} / 1 \times 10^{15} \mathrm{~cm}^{-2} \mathrm{~B}^{+}$implant was performed in an $\mathrm{n}$-type epi-layer grown on $6 \mathrm{H}-\mathrm{SiC}$ substrate.

In this exploratory study, all microwave anneals were performed in an uncontrolled ambient (air) 


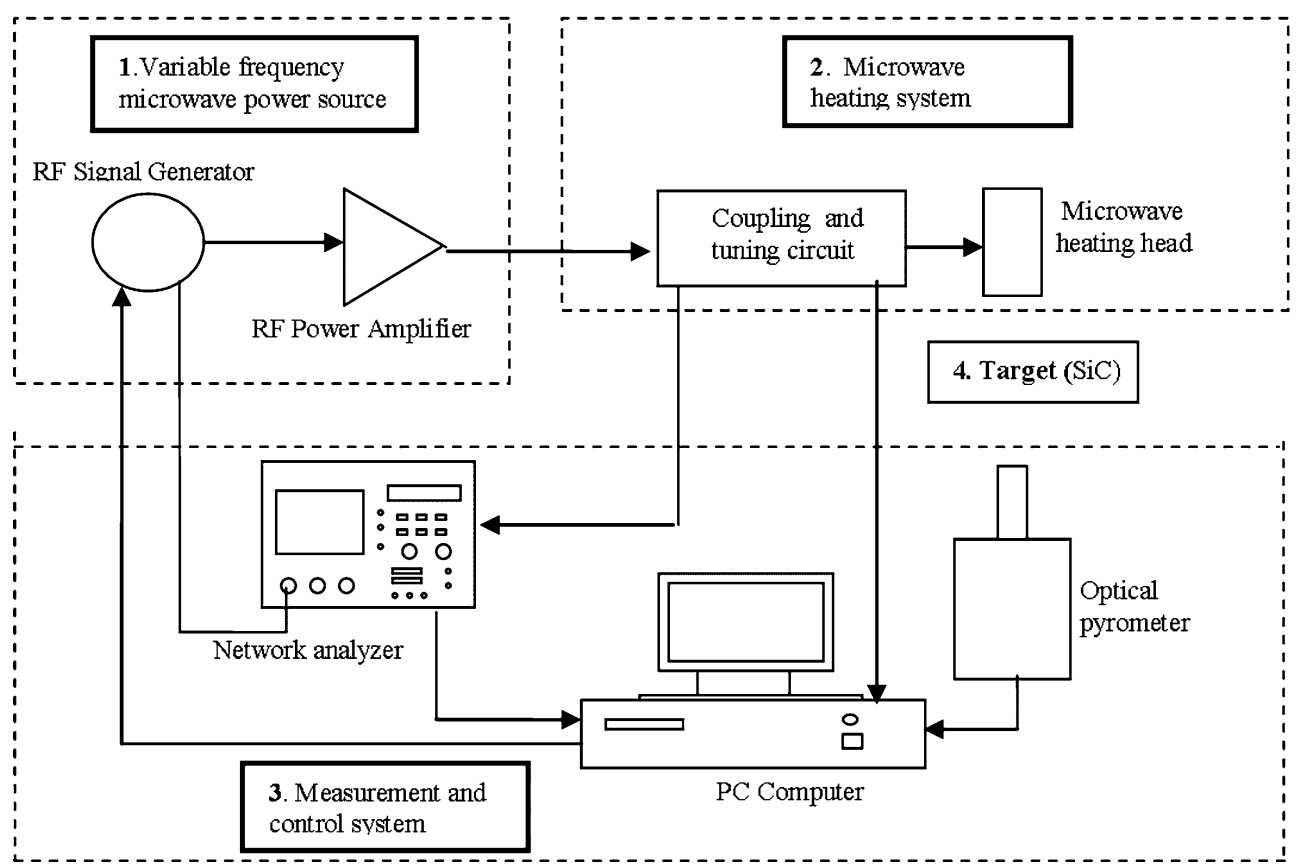

Fig. 1. Block diagram of the solid-state microwave annealing system.

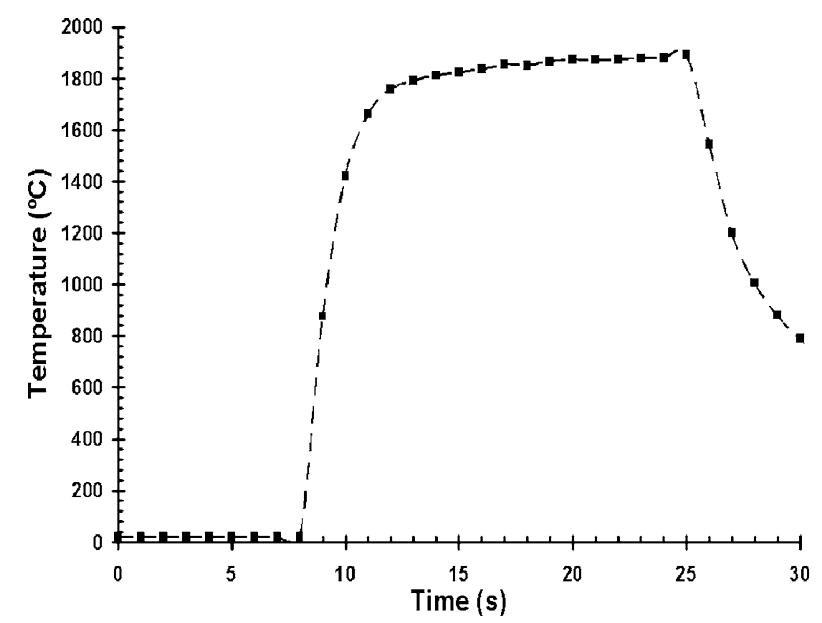

Fig. 2. A typical temperature-time cycle depicting the ultrafast heating and cooling rates of the solid-state microwave annealing system. The specimen being heated is a $5 \mathrm{~mm} \times 5 \mathrm{~mm}$ sample of $4 \mathrm{H}-\mathrm{SiC}$.

in the temperature range $1,570-1,970{ }^{\circ} \mathrm{C}$ for a duration of $10-35 \mathrm{~s}$. The samples were annealed using a $\mathrm{SiC}$ proximity cap to suppress $\mathrm{Si}$ sublimation during annealing. Conventional anneals were performed in a ceramic processing furnace, in the temperature range $1,400{ }^{\circ} \mathrm{C}-1,600{ }^{\circ} \mathrm{C}$ for a duration of 10-15 min. The conventional anneals were performed at a pressure of $1 \mathrm{~atm}$ in argon ambient. Hall measurements were performed using the van der Pauw geometry after electron beam deposition of $\mathrm{Ni}$ $(100 \mathrm{~nm})$ and $\mathrm{Ti} / \mathrm{Al}(20 \mathrm{~nm} / 100 \mathrm{~nm})$ ohmic contacts for $\mathrm{N}^{+}$- and $\mathrm{Al}^{+}$- implanted samples, respectively. The contacts were annealed at $1,000{ }^{\circ} \mathrm{C}$ for $1 \mathrm{~min}$ in an RTA furnace in 1 atm UHP argon.
On the annealed samples, Auger electron spectroscopy (AES) was performed in a Perkin Elmer 4U ESCA stainless steel UHV chamber equipped with a PHI 15-255G double pass cylindrical mirror analyzer. Experiments were performed at a base pressure of $7 \times 10^{-10}$ Torr. Sputtering was performed by backfilling the chamber with argon to a total pressure of $2 \times 10^{-5}$ Torr. To calibrate for the sputter rate, a commercially available $1,000 \AA \mathrm{SiO}_{2}$ film on a Si substrate was used. An atomic force microscope (AFM) operating in the contact mode was used to study the surface morphology of the annealed samples. Rutherford backscattering (RBS) spectra were acquired with a $2.275 \mathrm{MeV}$ energy $\mathrm{He}^{++}$beam at a backscattering angle of $160^{\circ}$ in channeled and rotating directions. Secondary ion mass spectrometry (SIMS) measurements were performed using a $10 \mathrm{kV} \mathrm{O}^{+}$primary ion beam at a current of $320 \mathrm{nA}$. The raster area was $150 \mu \mathrm{m} \times 150 \mu \mathrm{m}$. The depth scales were established by measuring the crater depths using a stylus profilometer and the concentration scales were established by equating the area under the curve of the as-implanted sample with the implant dose.

\section{RESULTS AND DISCUSSION}

\section{Surface Morphology of the Microwave- Annealed SiC Samples}

The surface morphology of the aluminum- and nitrogen-implanted $\mathrm{SiC}$ samples before and after microwave annealing was examined using AFM. The AFM images of $\mathrm{Al}$-implanted $4 \mathrm{H}-\mathrm{SiC}$ samples, annealed at $1,670{ }^{\circ} \mathrm{C} / 10 \mathrm{~s}$ and $1,850{ }^{\circ} \mathrm{C} / 35 \mathrm{~s}$, are shown in Figs. $3 \mathrm{a}$ and $3 \mathrm{~b}$, respectively. For comparison, an 

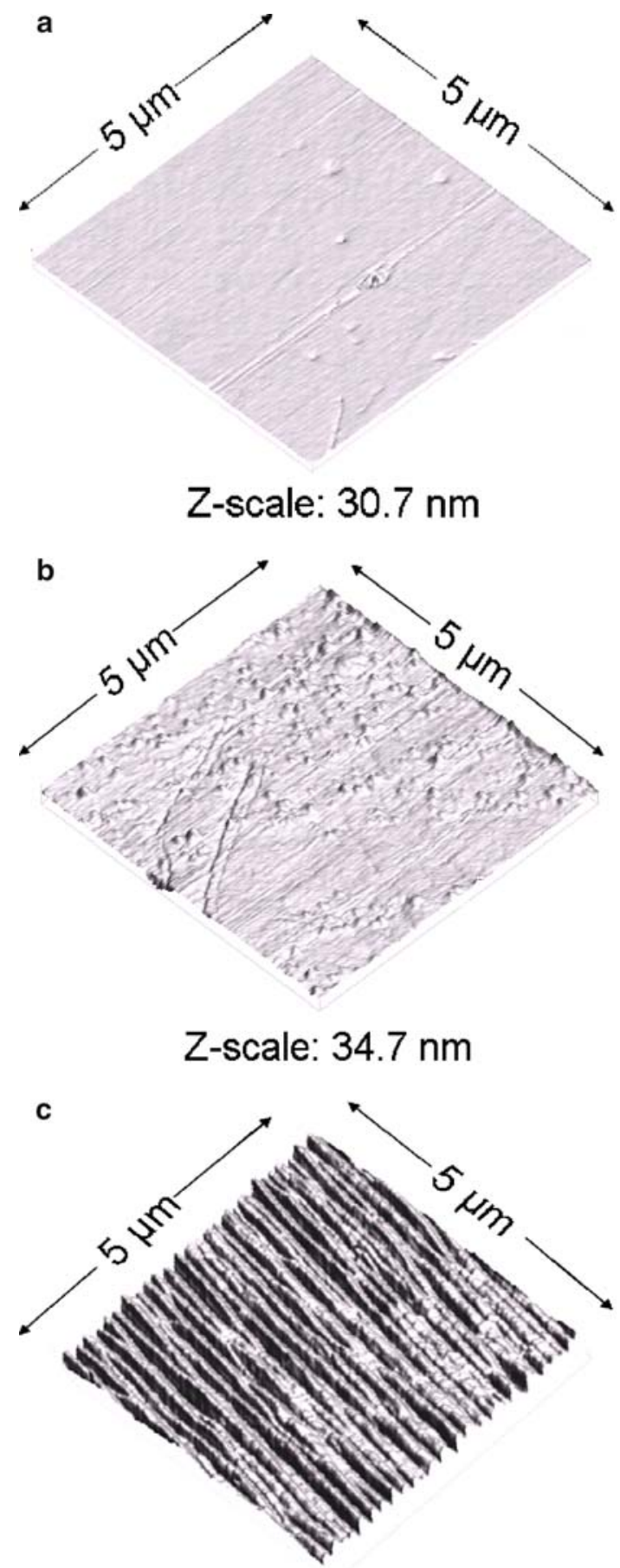

Z-scale: $18.2 \mathrm{~nm}$

Fig. 3. Atomic force microscope images of $\mathrm{Al}^{+}$-implanted $4 \mathrm{H}-\mathrm{SiC}$ samples: (a) microwave annealed at $1,670^{\circ} \mathrm{C}$ for $10 \mathrm{~s}$, (b) microwave annealed at $1,850{ }^{\circ} \mathrm{C}$ for $10 \mathrm{~s}$, and (c) furnace annealed at $1,500{ }^{\circ} \mathrm{C}$ for $15 \mathrm{~min}$.

AFM image of a furnace-annealed sample $\left(1,500{ }^{\circ} \mathrm{C} /\right.$ $15 \mathrm{~min}$ ) is shown in Fig. 3c. Figure 4 shows a plot of the root-mean-square (RMS) roughness extracted from the AFM images as a function of annealing temperature for $10 \mathrm{~s}$ to $35 \mathrm{~s}$ anneals on $\mathrm{Al}^{+}$-implanted SiC.

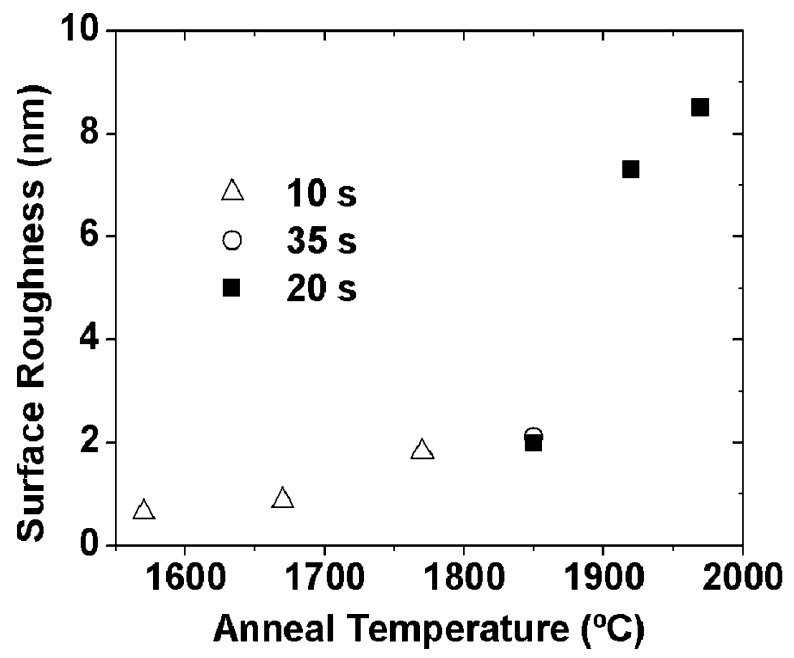

Fig. 4. Plot of the root mean square (RMS) roughness extracted from the AFM images as a function of annealing temperature for 10$35 \mathrm{~s}$ anneals for implanted $\mathrm{SiC}$.

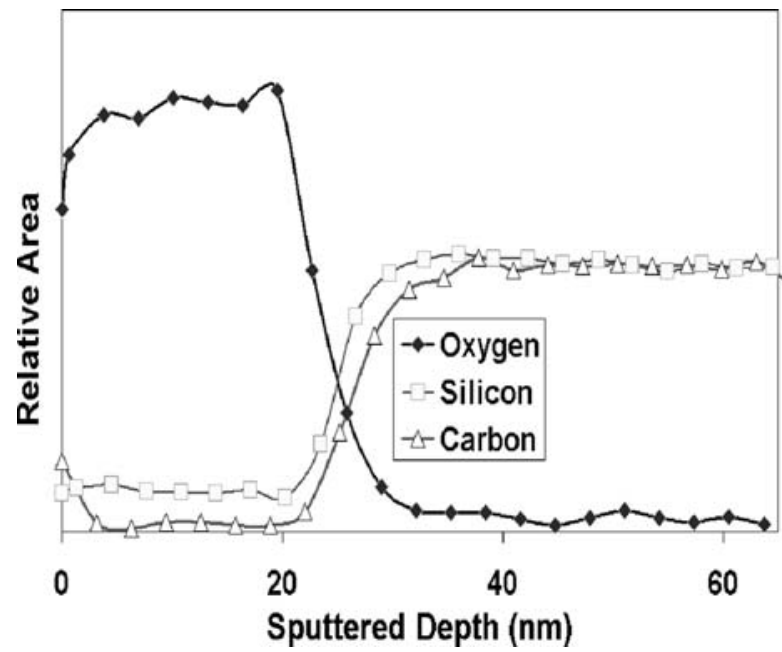

Fig. 5. A typical Auger sputter profile of the silicon oxide film formed during the microwave annealing performed at $1,820{ }^{\circ} \mathrm{C}$ for $10 \mathrm{~s}$.

From Fig. 4, it can be seen that the RMS roughness for the microwave-annealed samples, except for annealing temperatures $\geq 1,920^{\circ} \mathrm{C}$, is much smaller than the $6-\mathrm{nm}$ roughness observed in the $1,500^{\circ} \mathrm{C} /$ 15 min furnace-annealed sample. This result can be attributed to the short duration of the microwave annealing $(\approx 10-35 \mathrm{~s})$ compared to the furnace annealing $(\approx 15 \mathrm{~min})$ and also to the high temperature ramping rates of the microwave annealing. A lower surface roughness directly relates to an increase in the reliability during processing of submicrometer devices. Also, in the furnace-annealed samples, continuous long furrows running in one direction across the sample surface can be noticed. These furrows are supposed to be caused by the thermal desorption and re-deposition of species such as $\mathrm{Si}, \mathrm{SiC}_{2}, \mathrm{Si}_{2} \mathrm{C}$, etc. ${ }^{19,20}$ In the case of the micro- 


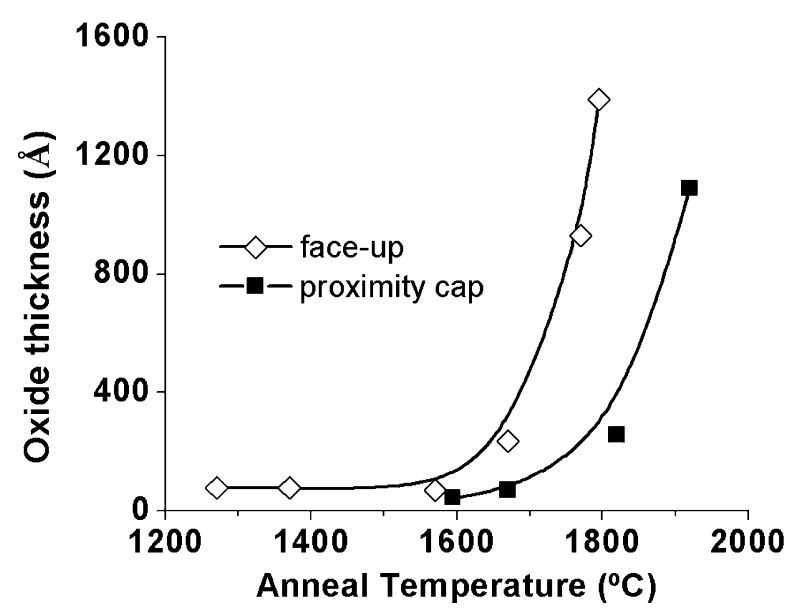

Fig. 6. The variation of oxide thickness as a function of annealing temperature for the proximity cap and the face-up (direct exposure) sample configurations for $10 \mathrm{~s}$ anneals.

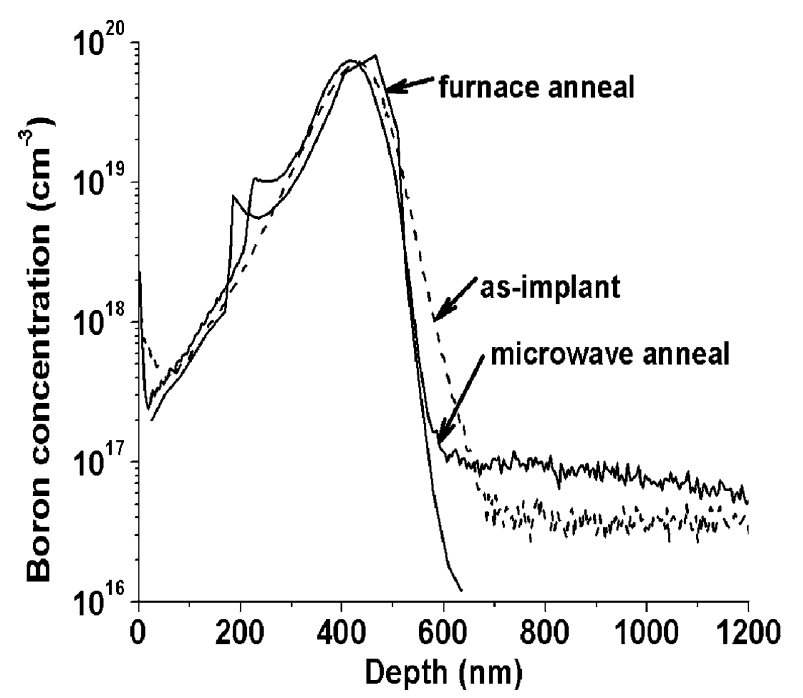

Fig. 7. SIMS depth profiles for $200 \mathrm{keV} / 1 \times 10^{15} \mathrm{~cm}^{-2} \mathrm{~B}^{+}$implantation in to $6 \mathrm{H}-\mathrm{SiC}$ before and after $1,670{ }^{\circ} \mathrm{C} / 10 \mathrm{~s}$ microwave annealing and $1,400{ }^{\circ} \mathrm{C} / 10 \mathrm{~min}$ furnace annealing.

wave-annealed samples, these furrows show up only in the samples annealed at temperatures $>1,770{ }^{\circ} \mathrm{C}$. Even then, for microwave anneals performed at $\leq 1,870{ }^{\circ} \mathrm{C}$, the heights of the furrows are much smaller compared to the furnace-annealed samples. However, the microwave anneals performed at the higher temperatures, $1,920^{\circ} \mathrm{C}$, and $1,970{ }^{\circ} \mathrm{C}$, do show a marked increase in surface roughness (Fig. 4). Also, the morphology of the furrows in microwave-annealed samples is similar to the furnace-annealed samples. Therefore, protection of the SiC surface with a graphite cap may be required for high-temperature $\left(>1,900{ }^{\circ} \mathrm{C}\right)$ microwave annealing in air.

\section{AES Study of the Surface of the Microwave- Annealed Samples}

Because the solid-state microwave (SSM) annealing of this work was performed in air, it is

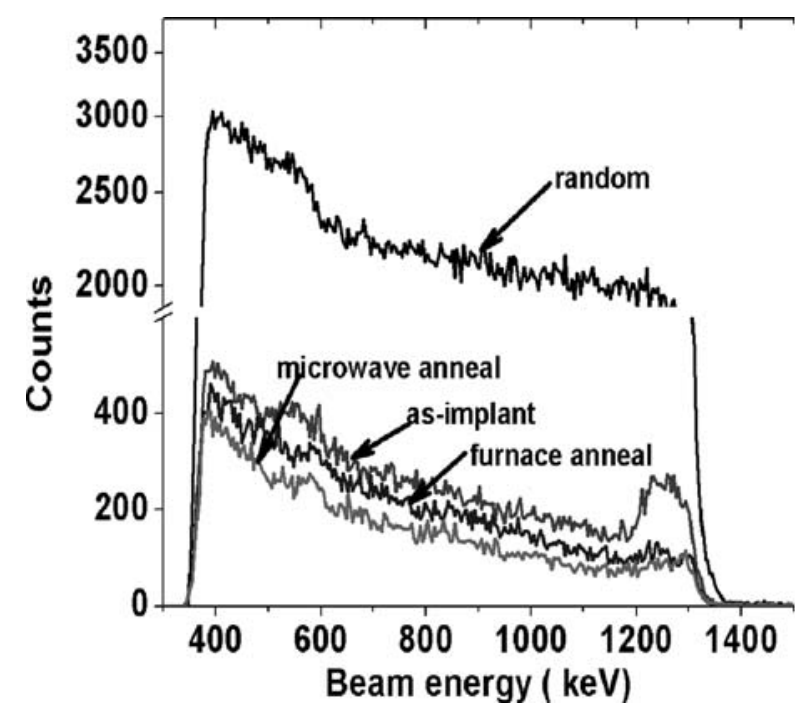

Fig. 8. RBS spectra on $50 \mathrm{keV} / 3.1 \times 10^{15} \mathrm{~cm}^{-2} \mathrm{~N}^{+}$-implanted $6 \mathrm{H}$ $\mathrm{SiC}$, before and after $1,770{ }^{\circ} \mathrm{C} / 25 \mathrm{~s}$ microwave annealing and $1,600^{\circ} \mathrm{C} / 15$ min conventional furnace annealing.

important to study the thermal oxide growth on the $\mathrm{SiC}$ surface. The AES sputter profiling was used to study the composition of the oxide layer and variation of oxide thickness with the annealing temperature. The samples used in this study were all virgin (unimplanted) $n$-type bulk $4 \mathrm{H}-\mathrm{SiC}$.

The oxide growth on two different $\mathrm{SiC}$ sample configurations was examined. In one case, the sample face was directly exposed to air. In another case, the sample to be studied was placed face down on another virgin $\mathrm{SiC}$ sample to mimic the proximity cap configuration used during postimplant annealing. A typical Auger sputter profile is shown in Fig. 5. The variation of oxide thickness with increasing temperature for the two sample configurations mentioned above is shown in Fig. 6. Upon performing Arrhenius fits for the data, the activation energies for $\mathrm{SiC}$ oxidation for both sample configurations were found to be similar $4.48 \mathrm{eV}$ for the direct exposure to air and $4.17 \mathrm{eV}$ for the proximity cap configuration). These values are in general agreement with the values reported ${ }^{21,22}$ earlier in the literature for parabolic SiC oxidation, which means that the oxidation rate is limited by the diffusion of the oxidizing species through the oxide film. ${ }^{23}$ Propensity for oxidation at a given temperature is less for the proximity cap configuration, resulting in shifting of the oxidation curve toward higher temperatures. This behavior is believed to be due to (a) increased partial pressure of Si- and Ccontaining species (due to sublimation from the surface of the capping sample) and (b) reduced oxygen partial pressure in the vicinity of the implanted sample for the proximity cap configuration, resulting in a reduced oxide growth rate. Thus, placing the sample in a proximity cap configuration during postimplant annealing has the added advantage of suppressing sublimation from 
Table I. Electrical Characteristics of Nitrogen-Implanted $6 \mathrm{H}-\mathrm{SiC}$

\begin{tabular}{|c|c|c|c|c|c|c|c|c|}
\hline $\begin{array}{l}\text { Anneal } \\
\text { Type }\end{array}$ & $\begin{array}{c}\text { Implant } \\
\text { Energy }\end{array}$ & $\begin{array}{c}\text { Implant } \\
\text { Temp., }{ }^{\circ} \mathbf{C} \\
\end{array}$ & $\begin{array}{c}\text { Total } \\
\text { Dose, } \\
\text { cm }^{-2}\end{array}$ & $\begin{array}{c}\text { Annealing } \\
\text { Temp./Time }\end{array}$ & $\begin{array}{c}\text { Sheet } \\
\text { Resistance, } \Omega / \square \\
\end{array}$ & $\begin{array}{c}\text { Sheet } \\
\text { Carrier } \\
\text { Concentration, } \\
\mathbf{c m}^{-2} \\
\end{array}$ & $\Phi, \%$ & $\begin{array}{c}\text { Carrier } \\
\text { Hall } \\
\text { Mobility, } \\
\mathbf{c m}^{2} / \mathrm{Vs} \\
\end{array}$ \\
\hline Furnace & $50 \mathrm{keV}$ & 700 & $3.1 \times 10^{15}$ & $1,500^{\circ} \mathrm{C} / 15 \mathrm{~min}$ & 2,390 & $1.24 \times 10^{14}$ & 4 & 21.1 \\
\hline Furnace & $50 \mathrm{keV}$ & 700 & $3.1 \times 10^{15}$ & $1,600^{\circ} \mathrm{C} / 15 \mathrm{~min}$ & 1,660 & $1.83 \times 10^{14}$ & 6 & 14 \\
\hline Microwave & $50 \mathrm{keV}$ & 700 & $3.1 \times 10^{15}$ & $1,770^{\circ} \mathrm{C} / 25 \mathrm{~s}$ & 967 & $4.84 \times 10^{14}$ & 15.6 & 13.4 \\
\hline Furnace & $15-280 \mathrm{keV}$ & $\mathrm{RT}$ & $1.35 \times 10^{15}$ & $1,600{ }^{\circ} \mathrm{C} / 15 \mathrm{~min}$ & 333 & $4.1 \times 10^{14}$ & 30.4 & 46 \\
\hline Microwave & $15-280 \mathrm{keV}$ & $\mathrm{RT}$ & $1.35 \times 10^{15}$ & $1,620^{\circ} \mathrm{C} / 10 \mathrm{~s}$ & 666 & $2.079 \times 10^{14}$ & 15.3 & 45.1 \\
\hline Furnace & $15-280 \mathrm{keV}$ & 700 & $2.7 \times 10^{15}$ & $1,600^{\circ} \mathrm{C} / 15 \mathrm{~min}$ & 290 & $8.6 \times 10^{14}$ & 31.2 & 25 \\
\hline Microwave & $15-280 \mathrm{keV}$ & 700 & $2.7 \times 10^{15}$ & $1,620^{\circ} \mathrm{C} / 10 \mathrm{~s}$ & 407 & $9.8 \times 10^{14}$ & 36.2 & 15.7 \\
\hline Furnace & $50 \mathrm{keV}-4 \mathrm{MeV}$ & 700 & $1.57 \times 10^{15}$ & $1,600{ }^{\circ} \mathrm{C} / 15 \mathrm{~min}$ & 211 & $5.96 \times 10^{14}$ & 38 & 50 \\
\hline Microwave & $50 \mathrm{keV}-4 \mathrm{MeV}$ & 700 & $1.57 \times 10^{15}$ & $1,570{ }^{\circ} \mathrm{C} / 10 \mathrm{~s}$ & 695 & $2.58 \times 10^{14}$ & 16.4 & 35 \\
\hline Microwave & $50 \mathrm{keV}-4 \mathrm{MeV}$ & 700 & $1.57 \times 10^{15}$ & $1,670{ }^{\circ} \mathrm{C} / 10 \mathrm{~s}$ & 391 & $3.3 \times 10^{14}$ & 21 & 48.5 \\
\hline
\end{tabular}

Table II. Electrical Characteristics of Aluminum-Implanted 4H-SiC

\begin{tabular}{|c|c|c|c|c|}
\hline $\begin{array}{l}\text { Annealing } \\
\text { Temp./Time }\left({ }^{\circ} \mathrm{C} / \mathrm{s}\right)\end{array}$ & $\begin{array}{c}\text { Sheet } \\
\text { Resistance }(\Omega / \square)\end{array}$ & $\begin{array}{c}\text { Sheet } \\
\text { Carrier Concentration }\left(\mathrm{cm}^{-2}\right)\end{array}$ & $\underset{(\%)}{\Phi}$ & $\begin{array}{c}\text { Hole } \\
\text { Mobility }\left(\mathrm{cm}^{2} / \mathrm{Vs}\right)\end{array}$ \\
\hline $1,670 / 10$ & $1.7 \times 10^{5}$ & $1.05 \times 10^{12}$ & 0.0004 & 35 \\
\hline $1,770 / 10$ & $1.15 \times 10^{5}$ & $1.95 \times 10^{12}$ & 0.07 & 28 \\
\hline $1,800 / 30$ & $11.2 \times 10^{4}$ & $1.97 \times 10^{12}$ & 0.07 & 28.3 \\
\hline $1,850 / 35$ & $7.0 \times 10^{3}$ & $7.3 \times 10^{13}$ & 2.7 & 12 \\
\hline $1,870 / 30$ & $3.5 \times 10^{4}$ & $1.5 \times 10^{13}$ & 0.5 & 11.9 \\
\hline $1,920 / 20$ & $15.55 \times 10^{4}$ & $1.18 \times 10^{12}$ & 0.0004 & 34 \\
\hline $1,970 / 20$ & $33.81 \times 10^{4}$ & $6.67 \times 10^{11}$ & 0.0005 & 27.7 \\
\hline
\end{tabular}

implanted sample and reducing the thickness of the unintentional thermally grown oxide layer on this sample. Finally, it should be noted that even though the anneals in this exploratory study were performed in air, we are currently in the process of developing a chamber with a controlled environment for future anneals. This is because a significant thickness of the implanted layer may be consumed, if the anneals are performed in air at very high temperatures $\left(>1,800^{\circ} \mathrm{C}\right)$. As mentioned before, such high temperatures are required for high implant activation. Future anneals are planned in nitrogen, argon, or xenon ambient.

\section{SIMS Study on the Thermal Stability of Boron- Implanted SiC}

It is well known that dopants such as $\mathrm{N}, \mathrm{Al}$, and $\mathrm{P}$ are thermally stable in SiC. No redistribution of these impurities was observed even in long duration conventional furnace anneals performed up to $1,700{ }^{\circ} \mathrm{C} .{ }^{8,24}$ On the other hand, the boron implant is known to redistribute in $\mathrm{SiC}$ even for low-temperature annealing. ${ }^{14,25}$ The small atomic size of boron resulting in a high transient enhanced diffusion is believed to be responsible for this behavior. In this work, we have performed SIMS measurements to study boron implant depth profiles in microwave-annealed SiC. The SIMS depth profiles performed for $200 \mathrm{keV} / 1 \times 10^{15} \mathrm{~cm}^{-2} \mathrm{~B}^{+}$implantation before and after $1,670{ }^{\circ} \mathrm{C} / 10 \mathrm{~s}$ microwave annealing are shown in Fig. 7. For comparison, the depth profile obtained for $1,400{ }^{\circ} \mathrm{C} / 10 \mathrm{~min}$ furnace annealing is also shown in Fig. 7. For both microwave annealing and furnace annealing, the boron implant formed an out-diffusion front, probably caused by the segregation of boron toward $\approx 0.7 R_{p}$, the depth where implant lattice damage is at its maximum. This is caused by the lattice strain at this location. A similar feature was observed in the depth profiles (not shown) performed for $1 \mathrm{MeV} /$ $1 \times 10^{15} \mathrm{~cm}^{-2} \mathrm{~B}^{+}$implantation after $1,670{ }^{\circ} \mathrm{C} / 10 \mathrm{~s}$ microwave annealing. Out-diffusion of the boron is less for the microwave annealing compared to the furnace annealing even though the microwave annealing was performed at a temperature $270{ }^{\circ} \mathrm{C}$ higher than the furnace annealing. This again establishes the attractiveness of ultrafast solidstate microwave annealing compared to the furnace annealing, which has much slower heating and cooling rates. A small degree of in-diffusion of the boron implant is also observed at the implant tail after microwave annealing.

\section{RBS Study}

The RBS spectra on $50 \mathrm{keV} / 3.1 \times 10^{15} \mathrm{~cm}^{-2} \mathrm{~N}^{+}$implanted material, before and after $1,770{ }^{\circ} \mathrm{C} / 25 \mathrm{~s}$ 
microwave annealing and $1,600{ }^{\circ} \mathrm{C} / 15$ min conventional furnace annealing, are shown in Fig. 8. This figure clearly demonstrates that the lattice quality of microwave-annealed material is better than the furnace-annealed material. The results show that the as-implanted sample has the highest level of lattice damage, with the backscattering signal reaching $14 \%$ of that of amorphous or randomly oriented SiC. The reason for such a low scattering yield in the as-implanted sample, even for such a high dose, is the elevated temperature $\left(700{ }^{\circ} \mathrm{C}\right)$ at which the implantation was performed. Elevated temperature implantation is known to promote a certain amount of in-situ dynamic annealing during the implantation process. The implant damage is present in the $0-200 \mathrm{~nm}$ depth range. The microwave-annealed sample shows the lowest (3.1\%) amount of backscattering, corresponding to the least crystal damage. The furnace-annealed sample shows slightly higher damage than the microwaveannealed sample for depths corresponding to 100$200 \mathrm{~nm}$. The increased backscattering signals for the as-implanted and the furnace-annealed samples for depths greater than $200 \mathrm{~nm}$ are due to dechanneling of the $\mathrm{He}^{++}$ion beam caused by damage in the $0-200 \mathrm{~nm}$ depth range.

\section{Electrical Characteristics of Nitrogen- Implanted SiC}

Electrical characteristics of the nitrogenimplanted/annealed $6 \mathrm{H}-\mathrm{SiC}$ material, obtained by van der Pauw Hall measurements at RT, are given in Table I. The implant energies and the doses pertaining to the samples are also included in the table. For comparison, the results on $\mathrm{SiC}$ samples annealed by a conventional Brew ceramic furnace are also included. The electrical activation $(\Phi)$ given in Table $I$ is the ratio of measured sheet carrier concentration at RT to the total implant dose. It is well known that due to a high donor ionization energy $(\approx 70-80 \mathrm{meV})$ in $\mathrm{SiC}$, the measured carrier concentration at RT does not represent the actual substitutional activation of the implant. ${ }^{25}$ By comparing the results of rapid SSM with that of furnace annealing for the $15-280 \mathrm{keV}$ multiple energy $\mathrm{N}^{+}$ implant, it can be stated that the implantation temperature plays an important role in the dopant activation process of rapid SSM annealing. For a $1620{ }^{\circ} \mathrm{C} / 10 \mathrm{~s}$ SSM annealing, the sheet resistance is closer to that of furnace annealing for the elevated temperature implantation, whereas it is only $50 \%$ of the corresponding furnace annealing value for the RT implantation. However, the sheet resistance values can be improved by increasing the annealing temperature and duration. For the $50 \mathrm{keV}-4 \mathrm{MeV}$ multiple energy $\mathrm{N}$-implant also a higher SSM annealing temperature/time than shown in Table I are required for removing the lattice damage and activating the $\mathrm{N}$-implant. For the single energy (50 keV) N-implanted sample, SSM annealing at $1,770{ }^{\circ} \mathrm{C}$ for $25 \mathrm{~s}$ yielded a much lower sheet resis- tance $(966 \Omega / \square)$ compared to the value $(1,666 \Omega / \square)$ for the furnace annealing at $1,600{ }^{\circ} \mathrm{C}$ for $15 \mathrm{~min}$. In spite of a higher sheet carrier concentration in the microwave-annealed sample, the carrier mobility is similar to that of the furnace annealing, indicating that the lattice damage is much smaller in the microwave-annealed sample. This observation corroborates with the RBS results shown in Fig. 8, which indeed show smaller lattice damage for the microwave-annealed sample.

\section{Electrical Characteristics of Aluminum Implanted SiC}

For the $600{ }^{\circ} \mathrm{C} \mathrm{Al}^{+}$implantation in $4 \mathrm{H}-\mathrm{SiC}$, the electrical characteristics measured at RT, by the van der Pauw Hall technique, are given in Table II. The percentage RT activation, $\Phi$ in Table II, is the ratio of net hole sheet concentration measured at $\mathrm{RT}$ to the total Al implant dose. It should be noted that the apparently smaller RT carrier activations measured for $\mathrm{Al}$ in comparison with $\mathrm{N}$ are a manifestation of the much higher carrier ionization energy for the $\mathrm{Al}$ acceptor $(\approx 200 \mathrm{meV})$ compared to the $\mathrm{N}$ donor $(\approx 70 \mathrm{meV})$ in $4 \mathrm{H}-\mathrm{SiC}$. It can be observed from Table II that even though the sheet resistance decreases with increasing annealing temperature, until we reach a temperature $>1,800{ }^{\circ} \mathrm{C}$, the carrier activation remains below $0.1 \%$ for the $10 \mathrm{~s}$ anneals. For $1,850{ }^{\circ} \mathrm{C} / 35 \mathrm{~s}$ anneal, we measured a maximum $\Phi$ of $2.7 \%$. Also, the lowest sheet resistance $(7 \mathrm{k} \Omega / \square)$ is measured for this particular anneal. To the best of our knowledge, the combination of this high activation and low sheet resistance are among the best reported to date. Negoro et al. ${ }^{26}$ (for an implant concentration $1.5 \times 10^{21} \mathrm{~cm}^{-3}$ to a depth of $0.2 \mu \mathrm{m}$ ) have reported a lower sheet resistance of $2.9 \mathrm{k} \Omega / \square$ and an activation $\Phi$ of $2 \%$, for an anneal time of $30 \mathrm{~min}$, at $1,800{ }^{\circ} \mathrm{C}$. However, they observed that their results degrade with an increasing annealing time, which is an indication that the increased p-type conductivity that they report may be related to the hopping conduction ${ }^{27}$ contributed by implant-generated defects in $\mathrm{SiC}$, which are known to exhibit p-type behavior, rather than by the chemical effect of substitutional Al. In hopping conduction, as the annealing time increases, the implant-generated defects are annealed and a drop in conductivity is observed. Also, at dopant concentrations in excess of $10^{21} \mathrm{~cm}^{-3}$ in $\mathrm{SiC}$, a Mott transition into a metallic phase (characterized by a very low mobility) has been observed in the literature. ${ }^{28,29}$

In Table II, for the anneals performed at temperatures beyond $1,900{ }^{\circ} \mathrm{C}$, a precipitous drop in carrier activation, and a consequent steep increase in the measured sheet resistance, can be observed (Table II). Because all anneals in this exploratory study were performed in the air, we can attribute the reason for this trend to the increased propensity for $\mathrm{SiC}$ oxidation at these high temperatures (Fig. 7). As a result, a major proportion of the 
implanted layer is being converted to silicon oxide, thereby decreasing the implant dose in the remaining material. This interpretation of the results suggests that microwave annealing in an inert atmosphere such as xenon, argon, or nitrogen is mandatory for high-temperature anneals.

\section{CONCLUSIONS}

Solid-state microwave annealing is an attractive method for rapid thermal annealing of implanted $\mathrm{SiC}$. In this technique, temperatures as high as $2,000{ }^{\circ} \mathrm{C}$ can be reached with a ramp-up rate of $>600{ }^{\circ} \mathrm{C} / \mathrm{s}$ and a fall rate of $400{ }^{\circ} \mathrm{C} / \mathrm{s}$. The electrical characteristics and lattice quality of the microwaveannealed material are better than the values obtained for conventional furnace anneals. Due to the short annealing durations, the redistribution of implanted boron is reduced in the microwave-annealed samples. Based on these above results, it is worth re-emphasizing that postimplantation annealing at higher temperatures and shorter durations is necessary for achieving optimum structural as well as electrical material properties. In this study, due to annealing in air, the samples were oxidized, so we are developing an annealing chamber for performing anneals in an inert atmosphere to prevent it. Also, with an appropriate heating head design, this rapid thermal processing technique has the potential for processing an entire 3 -in. SiC wafer.

\section{ACKNOWLEDGEMENTS}

We thank Abhishek Motayed, University of Maryland, for his help during the course of this study. This material is based on the work partially supported by a subcontract from LT Technologies under NSF SBIR Grant No. 0539321 and the Army Research Office (Dr. Prater) under Grant No. W911NF-04-1-0428.

\section{REFERENCES}

1. C.E. Weitzel, J.W. Palmour, A.H. Carter, K. Moore, K.K. Nordquist, S. Allen, C. Thero, and M. Bhatnagar, IEEE Trans. Electron. Dev. 43, 1732 (1996).

2. J.B. Tucker, S. Mitra, N. Papanicolaou, A. Siripuram, M.V. Rao, and O.W. Holland, Diamond Relat. Mater. 11, 392 (2002).
3. S.-H. Ryu, S. Krishnaswami, M. O'Loughlin, J. Richmond, A. Agarwal, J. Palmour, and A. Hefner, IEEE Electron. Dev. Lett. 25, 556 (2004).

4. J.H. Zhao, P. Alexandrov, J. Zhang, and X. Li, IEEE Electron. Dev. Lett. 25, 474 (2004).

5. K.J. Schoen, J.M. Woodall, J.A. Cooper, and M.R. Melloch, IEEE Trans. Electron. Dev. 45, 1595 (1998).

6. R. Singh, D.C. Capell, A.R. Hefner, J. Lai, and J.W. Palmour, IEEE Trans. Electron. Dev. 49, 2054 (2002).

7. T. Kimoto and N. Inoue, Phys. Status Solidi. A. 162, 263 (1997).

8. T. Troffer, M. Schadt, T. Frank, H. Itoh, G. Pensl, J. Heindl, H.P. Strunk, and M. Maier, Phys. Status Solidi. A 162, 277 (1997).

9. C. Thomas, C. Taylor, J. Griffin, W.L. Rose, M.G. Spencer, M. Capano, S. Rendakova, and K. Kornegay, MRS Proc. 572, 45 (1999).

10. G.J. Phelps, N.G. Wright, E.G. Chester, C.M. Johnson, and A. O'Neill, Semicond. Sci. Technol. 17, L17 (2002).

11. L. Zhu, M. Shanbhag, T.P. Chow, K.A. Jones, M.H. Ervin, P.B. Shah, M.A. Derenge, R.D. Vispute, T. Venkatesan, and A. Agarwal, Mater. Sci. Forum 433, 843 (2003).

12. Y. Negoro, K. Katsumoto, T. Kimoto, and H. Matsunami, J. Appl. Phys. 96, 224 (2004).

13. M.A. Capano, S. Ryu, J.A. Cooper, Jr., M.R. Melloch, K. Rottner, Karlsson, N. Nordell, A. Powell, and D.E. Walker, Jr. (1999) . J. Electron. Mater. 28:214.

14. K.V. Vassilevski, A.B. Horsfall, C.M. Johnson, and N.G. Wright, Mater. Sci. Forum 457, 989 (2004).

15. M.V. Rao, Solid State Electron. 47, 213 (2003).

16. M.A. Capano, S. Ryu, M.R. Melloch, J.A. Cooper Jr., and M.R. Buss, J. Electron. Mater. 27, 370 (1998).

17. Y. Tanaka, H. Tanoue, and K. Arai, J. Appl. Phys. 93, 5934 (2003).

18. S.D. Ruksell and A.D. Ramirez, Appl. Phys. Lett. 74, 3368 (2002).

19. K. Hata, A. Kawazu, T. Okano, T. Ueda, and M. Akiyama, Appl. Phys. Lett. 63, 1625 (1993).

20. V.R. Vathulya and M.H. White, Solid-State Electron. 44, 309 (2000)

21. S.C. Singhal, J. Mater. Sci. 11, 1246 (1976).

22. C. Raynaud, J. Non-Cryst. Sol. 280, 1 (2001).

23. T. Narushima, T. Goto, and T. Hirai, J. Am. Cer. Soc. 72, 1386 (1989).

24. G. Pensl, V. Afanasev, M. Bassler, M. Schadt, T. Troffer, J. Heindl, H. Strunk, M. Maier, and W. Choyke, Inst. Phys. Conf. Ser. 142, 275 (1996).

25. M.V. Rao, J.B. Tucker, M.C. Ridgway, O.W. Holland, N. Papanicolaou, and J. Mittereder, J. Appl. Phys. 86, 752 (1999).

26. Y. Negoro, T. Kimoto, H. Matsunami, F. Schmid, and G. Pensl, J. Appl. Phys. 96, 4916 (2004).

27. W.C. Mitchel, A.O. Evwaraye, S.R. Smith, and M.D. Roth, J. Electron. Mater. 26, 113 (1997).

28. K. Tone, S.P. Weiner, and J.H. Zhao, Electron. Lett. 33, 1904 (1997).

29. H. Wirth, D. Panknin, W. Skorupa, and E. Niemann, Appl. Phys. Lett. 74, 979 (1999). 